\title{
Interceptação Telefônica e a Investigação Criminal
}

A Interceptação Telefônica é um dos elementos que constituem a elucidação de um crime ou de uma autoria, contribuindo, na prática, para a compreensão a respeito do contexto que envolve o fato criminoso. Nesse sentido, surge a necessidade de refletir sobre o que diz a lei a respeito dessa captação da comunicação entre indivíduos, que é realizada por meio de um recurso tecnológico que é chamado de telefone. Enquanto dois interlocutores conversam, um terceiro escuta, sem o seu conhecimento. Pode ainda ocorrer, com o conhecimento de uma das pessoas que participam dessa comunicação. No caso da gravação clandestina, 0 próprio interlocutor grava, sem que o outro saiba. A legislação apenas regulamenta a escuta de terceiro, com o objetivo de produzir provas para a investigação criminal. Através de pesquisa bibliográfica, faz-se uma sistematização de obras já publicadas sobre a temática, coletando dados em livros, trabalhos acadêmicos e artigos científicos. Com o avanço tecnológico, a interceptação telefônica abrange qualquer forma de comunicação, incluindo mensagens de texto e de voz. Concluise que essa medida precisa ser realizada com autorização judicial prévia sob pena de invalidação. Mister, distingue-se a interceptação telefônica da quebra de sigilo telefônico: a primeira é a escuta; e a segunda tem a finalidade apenas de analisar os registros de ligações realizadas e o local em que o indivíduo estava no momento da ligação.

Palavras-chave: Interceptação Telefônica; Prova; Processo Penal.

\section{Telephone Interception and Criminal Investigation}

The Telephone Interception is one of the elements that constitute the elucidation of a crime or of an authorial, contributing, in practice, to the understanding about the context that involves the criminal fact. In this sense, there is a need to reflect on what the law says about this capture of communication between individuals, which is accomplished through a technological resource that is called a telephone. As two interlocutors talk, a third listens without their knowledge. It may also occur, with the knowledge of one of the people participating in that communication. In the case of clandestine recording, the speaker himself records without the other knowing. The legislation only regulates the hearing of third parties, with the purpose of producing evidence for the criminal investigation. Through bibliographic research, a systematization of works already published on the subject is done, collecting data in books, academic works and scientific articles. With technological advancement, telephone interception covers any form of communication, including text and voice messages. It is concluded that this measure must be carried out with prior judicial authorization under penalty of invalidation. Mister, the telephone interception is distinguished from the break of telephone secrecy: the first is listening; and the second is intended only to analyze the records of connections made and the place where the individual was at the time of the connection.

Keywords: Telephone Interception; Proof; Criminal Proceedings.

Topic: Direito Penal e Processo Penal

Reviewed anonymously in the process of blind peer.
Received: 22/06/2018

Approved: 28/08/2018
Carlos Alberto Silva

Faculdade Venda Nova do Imigrante, Brasil

betounit@hotmail.com

Carlos Eduardo Silva (iD)

Faculdade 8 de Julho, Brasil

http://lattes.cnpq.br/3700554054159220

http://orcid.org/0000-0001-8358-0263

carlos@sustenere.co

\section{Referencing this:}

SILVA, C. A.; SILVA, C. E.. Interceptação telefônica e a investigação criminal. Scientiam Juris, v.6, n.1, p.21-28, 2018. DOI:

http://doi.org/10.6008/SPC2318-3039.2018.001.0002

DOI: 10.6008/SPC2318-3039.2018.001.0002 


\section{INTRODUÇÃO}

O estudo tem o objetivo de analisar a Interceptação Telefônica como forma de produção de provas. A interceptação ocorre quando uma terceira pessoa capta a comunicação telefônica de interlocutores sem o conhecimento deles. A gravação é considerada clandestina quando é feita por um dos interlocutores, sem que o outro saiba. A legislação trata da interceptação e da escuta, pois são realizadas com a presença de uma terceira pessoa que não está presente diretamente na comunicação.

Por se tratar de um meio de produção de provas e objeto da Investigação Criminal, a interceptação telefônica deve ser realizada de acordo com o que diz a lei. Diante das mudanças tecnológicas que a sociedade realiza, a legislação estabelece a possibilidade de interceptar qualquer comunicação informática ou telemática, seja por mensagem de texto ou de voz, com o uso de aplicativos de celulares. A realização dessa investigação requer autorização judicial prévia, sob pena de se tornar inválida juridicamente.

Mesmo que os interlocutores autorizem posteriormente o uso da escuta como meio de prova, a inexistência de uma autorização prévia gera a invalidade. Segundo o Superior Tribunal de Justiça, não há validade quando realizada sem que haja previamente uma autorização judicial, mesmo que um dos interlocutores a autorize (STJ, HC 161.053/SP). A prova precisa ser lícita, seguindo as regulamentações da Lei no 9296/96, denominada de Lei da Interceptação Telefônica.

Daí a necessidade de refletir sobre a interceptação telefônica, compreendendo seu conceito, suas características e a distinção em relação ao sigilo telefônico. Sabe-se que interceptar é acessar o conteúdo da conversa, enquanto a quebra de sigilo tem a finalidade de obter informações sobre o registro de ligações efetuadas e recebidas, bem como o local em que o interlocutor estava no momento do crime. Segundo a Lei de Interceptação Telefônica, essa ação caracteriza uma forma de investigação, independente da presença de inquérito policial. Quanto às autoridades competentes para solicitar ordem judicial, estão os representantes da polícia e do Ministério Público.

A pesquisa é de natureza bibliográfica e descritiva, realizada por meio de sistematização de obras já publicadas e que abordam a temática, como livros, revistas e artigos científicos e trabalhos acadêmicos. Visase responder ao seguinte questionamento: qual a importância da interceptação telefônica na investigação criminal? Ter-se-á como hipótese a compreensão do crime e da autoria a través da análise da comunicação dos suspeitos. Inicialmente se conceitua e caracteriza a interceptação telefônica, para posteriormente refletir sobre a sua importância para a investigação de crimes.

\section{DISCUSSÃO TEÓRICA}

\section{Interceptação Telefônica}

A interceptação telefônica, enquanto forma de produção de provas, precisa atender os requisitos legais. A autorização da Interceptação Telefônica é regulamentada pela Lei no 9.296/96, que estabelece essas exigências. Logo, é preciso que seja por um objetivo lícito, com finalidade criminal e com prévia autorização. Segundo Silva (2014), o uso desse instituto é ligado à investigação criminal. O interceptor capta uma conversa 
telefônica sem conhecimento. A escuta ocorre quando um dos interlocutores tem conhecimento da presença de terceiro.

A gravação da conversa de forma clandestina ocorre pela ação de um dos interlocutores. Pode ocorrer a interceptação ambiental, na qual a escuta ocorre no ambiente, sem que os participantes da comunicação saibam. A legislação regulamenta a interceptação telefônica e a escuta telefônica. Raboneze (2012) esclarece que a gravação ambiental tem a finalidade de obtenção da confissão. Assim, o interceptor grava e capta com amparo jurídico, tornando-se prova lícita, enquanto a clandestinidade é ilícita e não é admitida no processo. É essencial que haja uma autorização judicial prévia, que é concedida de acordo com a verificação de alguns requisitos, conforme se analisa no organograma 1.

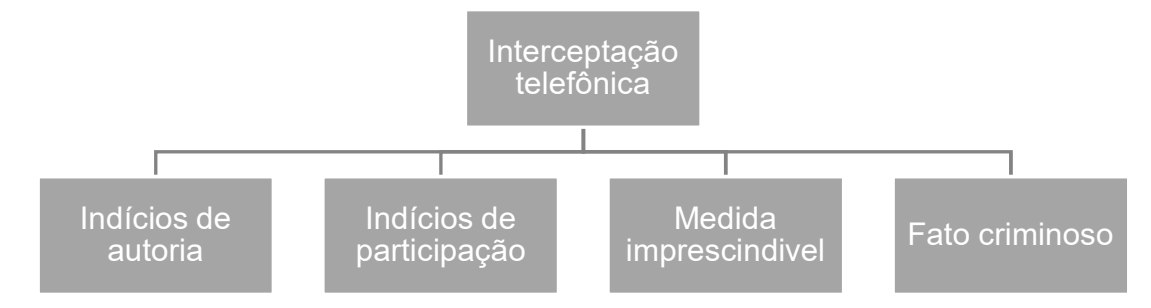

Organograma 1: Requisitos para concessão de interceptação telefônica. Fonte: Távora (2016)

Para que a interceptação seja concedida, é preciso que se tenham fortes indícios de que o investigado foi autor ou participou do crime, tornando a medida imprescindível para a compreensão dos fatos e comprovação dessa autoria. Outro requisito importante diz respeito ao crime passível de reclusão. Essa medida é considerada grave, uma vez que viola um direito fundamental. Daí a importância de ser decretada apenas em casos essenciais, nos quais a pessoa precisa ser investigada para a compreensão de sua relação com um delito.

É necessário esclarecer que a interceptação telefônica viola um direito fundamental do indivíduo, sendo admitida em casos excepcionais e imprescindíveis. A ordem judicial é o alicerce para que o interceptor utilize a informação adquirida como prova lícita. Nesse contexto, não há liberdade absoluta, sendo essencial defender o interesse público. Oliveira (2014) explica que não pode ser realizada como elemento inicial de uma investigação. A interceptação de prospecção ocorre sem que haja indício de autoria e não é aceita juridicamente. Verifica-se que é uma medida imprescindível, realizada apenas quando não houverem outros meios de coleta de provas. A violação da intimidade de um cidadão precisa ser realizada com fundamentos plausíveis e aceitáveis.

Não cabe interceptação telefônica quando outros elementos informativos da autoria estiverem presentes, como testemunhas e provas periciais. Por conseguinte, trata-se de uma medida excepcional que é realizada quando não houver mais meios suficientes para compreender e elucidar um crime. Apenas crimes punidos de reclusão cabem essa concessão judicial, a exemplo dos homicídios. Nos casos de serendipidade, isto é, quando se observa uma descoberta acidental e surge a necessidade de utilizar a prova para esses novos fatos, é válida a escuta da comunicação dos interlocutores (STJ, RHC 28794/RJ).

Assim, a interceptação telefônica é usada para investigar crimes que são punidos com detenção, mesmo que tenham sido descobertos após uma investigação inicial de crime com pena de reclusão. Nesse 
sentido, qualquer interlocutor pode ser investigado. Outro fato que merece análise é a prova emprestada, que pode ser usada no processo administrativo disciplinar (TAVORA, 2016). A inexistência de autorização judicial torna a prova ilícita o que a coloca na condição de imutável, não havendo mais licitude. É imprescindível que a interceptação telefônica seja solicitada à autoridade competente para que tenha validade jurídica, conforme informativo 742, do STF:

Na espécie, no curso de investigação da polícia federal destinada a apurar delitos contra a Administração Pública Federal, praticados por grupo de empresários, as interceptações telefônicas, devidamente autorizadas por juízo de 1으 grau, revelaram que delitos de outra natureza estariam sendo praticados por grupo diverso, voltado à obtenção ilícita de lucros por meio de contratação e execução de obras públicas em vários Estados-membros com fraude em licitações. Diante do envolvimento de autoridades com prerrogativa de foro, determinara-se o deslocamento do feito para o STJ, cuja relatora autorizara a interceptação telefônica e sua prorrogação, o que culminara na indicação do paciente como envolvido em grupo criminoso. A Turma destacou que decisão proferida no STJ, ao autorizar a interceptação telefônica, estaria fundamentada ante a complexidade do esquema a envolver agentes públicos e políticos, aliada à dificuldade em se colher provas tradicionais. (HC 119.770/BA).

Ante o exposto, pode-se verificar que a interceptação telefônica é um meio de investigação que viola o direito fundamental à intimidade, sendo necessária a autorização judicial para que seja realizada, que é dada por autoridade competente após avaliar a presença de todos os requisitos legais. A autoridade policial requere durante o período de investigação; já o Ministério Público pode requerer durante o curso do processo, havendo omissão legal quanto à possibilidade de a defesa fazer a solicitação, visando a formação de provas que lhe favoreçam.

Esse requerimento ocorre em segredo, não sendo possível o investigado se manifestar a respeito dos fatos, para não frustrar os objetivos esperados com a escuta telefônica. Essa oitiva é realizada após a realização da interceptação, já com as provas produzidas. De acordo com a Súmula Vinculante no 14, é direito do defensor e do acusado acessar essa documentação. As conversas são transcritas, cabendo à defesa acessar a sua integralidade. Entretanto, de acordo com Tourinho Filho (2015), apenas os minutos que interessam à investigação devem ser observados, não sendo relevante transcrever várias horas de conversa.

A gravação integral, quando não apresenta interesse para as partes, não precisa ser considerada durante o processo (HC 278794/SP). Mesmo que a gravação não seja integral, as partes podem ter a gravação disponibilizada. A interceptação telefônica não precisa ser realizada pela autoridade policial, principalmente quando os investigados fizerem parte dessa instituição. De acordo com Souza (2016), o Ministério Público tem competência para realizá-la, desde que o Poder Judiciário o autorize.

Analisando a problemática, verifica-se que o artigo 60, da Lei no 9.296/1996, estabelece que não é apenas a autoridade policial que realiza a interceptação telefônica, embora sempre esteja responsável pela presidência da investigação. É importante destacar que não há nulidade das provas, caso o Ministério Público realize a escuta e transcrição da interceptação, já que é considerada uma divisão de tarefas.

A autoridade policial tem competência para solicitar serviço técnico em relação à escuta telefônica, encaminhado o resultado para o juiz competente, devendo descrever tosos os procedimentos realizados durante a investigação. Ainda de acordo com a Lei 9.296/96, em seu artigo 10ำ, a realização de interceptação 
telefônica sem a autorização judicial caracteriza crime, por se tratar de uma violação ao direito fundamental do indivíduo.

Rangel (2015) explica que a inexistência de ordem judicial inviabiliza a interceptação telefônica, cabendo punição para aqueles que violam o direito à intimidade. Quando se fala em intervir, refere-se ao fato de introduzir um terceiro em uma conversa entre duas ou mais pessoas, tendo como objetivo coletar informações. Rangel (2015) afirma que se trata de uma situação em que alguém se coloca entre as pessoas que conversam, intrometendo-se e tomando conhecimento do que está sendo tratado.

Gomes (2014) esclarece que o sigilo das comunicações tem sido protegido juridicamente, com tutela na Constituição Federal de 1988, sendo a interceptação telefônica uma forma de garantia do conhecimento de um fato criminoso e prejudicial à sociedade. Nela, um terceiro participa de uma comunicação, com a finalidade de coletar provas sobre a ocorrência de um ato criminoso.

Segundo o artigo 5o da Lei no 9.296/96, a interceptação telefônica é realizada em um período de quinze dias, que podem ser renovados desde que comprovada a necessidade e a sua indispensabilidade para compor o conjunto probatório. É importante limitar essa ação investigativa, já que ela tem como principal característica a restrição de um direito fundamental do cidadão. De acordo com Mendes (2015), o sigilo das comunicações deve ser respeitado, justificando-se apenas a sua quebra, em casos excepcionais, como é a investigação de um crime punível com reclusão. Nesse sentido, a imposição de limites para o período em que um terceiro, mesmo que por ordem judicial, possa restringir o sigilo da comunicação, é bastante viável. Em jurisprudência do Tribunal do Rio Grande do Sul, se tem a seguinte decisão:

TJ-RS - Habeas Corpus HC 70061135893 RS (TJ-RS) Data de publicação: 07/10/2014

Ementa: HABEAS CORPUS. ASSOCIAÇÃO PARA O TRÁFICO. ALEGADA ILICITUDE

DAS INTERCEPTAÇÕES TELEFÔNICAS. INTERCEPTAÇÃO POR PROSPECÇÃO. NECESSIDADE DE PRÉVIA APURAÇÃO DOS FATOS. SERENDIPIDADE DAS INTERCEPTAÇÕES. PRORROGAÇÃO E TRANSCRIÇÃO INTEGRAL DAS ESCUTAS. EXCESSO DE PRAZO. SÚMULA 52 DO STJ. 1. Paciente preso preventivamente pela prática, em tese, do delito de associação para o tráfico. A impetrante sustenta a ilicitude das interceptações telefônicas, pois realizadas sem prévia apuração dos fatos, postulando o desentranhamento das interceptações e das demais provas delas derivadas, e a declaração de nulidade absoluta do feito, desde a origem. Alega que as interceptações foram renovadas inúmeras vezes, sem a necessária comprovação da sua indispensabilidade e fundamentação. Sustenta que houve violação aos princípios da ampla defesa e contraditório, pois as interceptações telefônicas não foram integralmente transcritas. Alega que há excesso de prazo na formação da culpa, pois o paciente está preso há sete meses, sem que a instrução tenha sido encerrada e sem que exista previsão de encerramento. 2. Não há falar em interceptação por prospecção no presente caso, tendo em vista as diligências prévias realizadas pela autoridade policial. Demonstração da existência de indícios de autoria e da indispensabilidade das interceptações, nos termos da Lei no 9.296 /96. 3. Serendipidade das interceptações. Descoberta fortuita de fato conexo ao investigado e/ou de continência. Validade da prova... obtida. Precedente. 4. Possibilidade de prorrogações sucessivas das interceptações quando se mostrarem necessárias à apuração do fato. Precedentes. 5. Desnecessidade de transcrição integral das interceptações. Possibilidade de transcrição dos trechos que interessam à denúncia. Precedentes. 6 . Alegação de excesso de prazo ficou superada pelo encerramento da instrução (Súmula 52 do STJ). 7. Inexistência de constrangimento ilegal. ORDEM DENEGADA. (Habeas Corpus № 70061135893, Primeira Câmara Criminal).

Nesse contexto, verifica-se que o prazo para a interceptação telefônica é limitado por quinze dias, havendo a possibilidade de prorrogação, quando justificada. A utilização desse meio de coleta de prova é 
excepcional e deve ser pautada no alicerce da indispensabilidade, para que se possa apurar os fatos criminosos, uma vez que sem ela, se torna difícil obter a comprovação da autoria. Diante da prática jurídica, o legislador se viu diante da necessidade de legislar e regulamentar esse dispositivo. Esse conhecimento a respeito da comunicação alheia se torna imprescindível para o processo penal. Essa ferramenta jurídica é utilizada pelas agências de controle, como forma de produção de provas para o processo penal, conforme se observa no organograma 2.

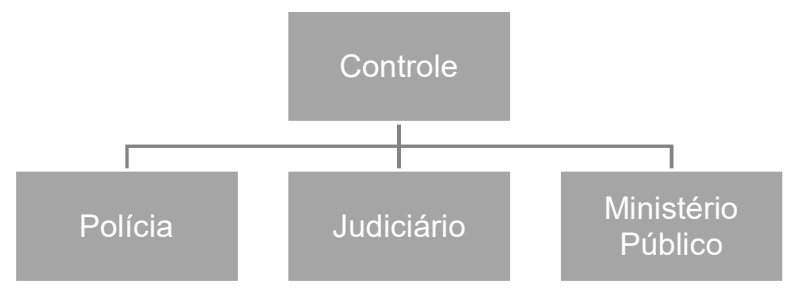

Organograma 1: Agências de Controle. Fonte: Távora (2016)

É necessário compreender que os dados telefônicos não estão inseridos entre os aqueles que o sigilo acoberta. Dessa forma, é possível identificar o nome, a qualificação e o endereço de um titular de uma linha telefônica, durante a investigação de um crime. Logo, para que o Ministério Público ou a autoridade policial tenham acesso a esses dados, não é necessário solicitar a ordem judicial. De acordo com Capez (2013), a interceptação telefônica é a escuta e a gravação de um telefonema, sem que as pessoas envolvidas no diálogo tenham conhecimento do fato. Stricto sensu, pode-se dizer que ela caracteriza o fato de uma terceira pessoa violar a conversa de duas ou mais, sem que se saiba. Moraes (2015) define como a captação a gravação da conversa realizada por meio do telefone ou qualquer outro meio eletrônico.

Por se tratar de uma intromissão, as pessoas envolvidas na ligação não têm conhecimento de um terceiro escutando. A escuta, segundo Gomes (2014), é a violação da conversa telefônica de duas ou mais pessoas, com o conhecimento de, pelo menos, uma delas. Nesse contexto um dos interlocutores conhece a situação de captação. A terceira pessoa ouve e grava; nada obstante, pelo menos um dos interlocutores tem conhecimento e autorizou a participação desse terceiro. Nesse tipo de interceptação telefônica, verifica-se a presença da autorização e do consentimento do interlocutor, havendo a violação da intimidade daquele que desconhece o fato. Para Pellegrini (2013), entende que a permissão de um dos interlocutores representa o exercício de um direito, que é marcado pelo controle de sua comunicação.

A tutela da inviolabilidade em relação à interceptação telefônica ocorre porque é preciso que um terceiro invada o dialogo mantido por duas ou mais pessoas; ratifica-se a importância da ordem judicial e da natureza criminal da investigação. As provas são utilizadas para possibilitar ao juiz o conhecimento necessário a respeito dos fatos que são alegados pelas partes envolvidas no processo. Assim, insere-se o entendimento de todas as circunstâncias que envolvem o que está sendo alegado, sejam elas objetivas ou não. Para que a sentença seja dada de forma segura e se passe a surtir o efeito almejado, torna-se essencial a fundamentação e a convicção a respeito da relação entre o direito e o pedido (SOUZA, 2016).

A gravação clandestina caracteriza-se pela inexistência de terceiro, já que é realizada por um dos interlocutores, registrando a conversa sem o conhecimento do outro. Streck (2015) explica a importância de 
distinguir a interceptação telefônica da gravação realizada por um dos participantes da comunicação, que é a presença ou não de terceira pessoa. Gravar a conversar não é considerado ilícito, já que não ocorre violação ao direito por terceiro. Embora contrarie o artigo 153 do Código penal, que prevê a possibilidade de violação ao segredo, sua licitude está associada à necessidade de coletar provas para o processo penal.

\section{CONCLUSÃO}

Foi possível verificar que a inviolabilidade do sigilo das comunicações telefônicas está prevista no artigo 5으, inciso XII, da Constituição Federal. Entretanto, a interceptação telefônica caracteriza um instituto jurídico, utilizado na investigação criminal, para coletar provas a respeito da materialidade e autoria de um delito.

Com o advento da Lei № 9.296/1996, a intimidade do cidadão passou a ser preservada, já que a interceptação telefônica só é admitida em casos extremamente necessários e com a ordem judicial, avaliando a sua importância para a compreensão de um crime; surge para disciplinar a matéria e estabelecer as regras de utilização do meio eletrônico como prova. Assim, o Estado adquire meios de lutar contra a criminalidade, sem que tenha que violar indiscriminadamente os direitos do cidadão brasileiro.

É verificado que a interceptação telefônica se fundamenta em qualquer meio de comunicação que utilize os meios eletrônicos, telefones, aplicativos de celular e correio eletrônico. Com o avanço tecnológico, a comunicação entre as pessoas tem se diversificado, sendo necessário combater a criminalidade de forma mais ampla. A Lei de Interceptação Telefônica cita os requisitos necessários para que seja possível realizar a interferência e a gravação de conversa de terceiros. Entre eles, está o forte indício da existência de um crime e da participação das partes envolvidas na comunicação.

Outro requisito é a impossibilidade de coletar provas de outra forma, já que as investigações indicam o forte indício, mas não comprovam a autoria. Por fim, o crime cometido pelas partes deve ser punido com reclusão, uma vez que não se justifica a violação de um direito para coletar provas de um crime de menor potencial ofensivo. A admissão da interceptação telefônica deve estar fundamentada em elementos suficientes da autoria de quem será interceptado.

Com a indicação de provável prática criminosa, deve-se recorrer ao meio de interceptação telefônica para apurar os fatos e formar o conjunto probatório. Em caso de provas suficientes sobre a autoria do crime, não se pode falar em violação do direito ao sigilo telefônico. As pessoas precisam ter os direitos à intimidade e liberdade de comunicação respeitados, a menos que seja imprescindível para a solução de um crime.

Cabe ao juiz avaliar o efeito dessa ação investigatória, optando por autorizar ou não a quebra do sigilo telefônico. A fundamentação da medida é essencial para que se avalie se é ou não necessário realizála. Entre os requisitos, está o caráter indispensável para a produção do conjunto probatório.

As interceptações penais, cuja punição é de detenção, apenas permitem a interceptação telefônica se estiverem associadas a crimes que sejam punidos com reclusão. Esses encargos, previstos pela Lei $n$ o 9.296/1996, demostram o caráter excepcional da medida, estabelecendo restrições e preservando o direito à intimidade do indivíduo, bem como das pessoas envolvidas em sua comunicação. 
O presente artigo teve como objetivo analisar a utilização da interceptação telefônica como meio de prova, uma vez que ela se torna essencial para o processo penal. O conjunto probatório é um elemento essencial para a defesa, evitando que pessoas sejam condenadas sem qualquer requisito legal. É essencial, para que a verdade seja alcançada e a autoria de um crime conhecida.

O direito à intimidade não pode ser violado sem qualquer fundamento que o justifique. $O$ estudo conceituou e caracterizou a interceptação telefônica, descrevendo os seus tipos e distinguindo-a da gravação clandestina; analisou a Lei no 9.296/1996, cuja finalidade é regulamentar esse procedimento investigativo, preservando o direito fundamental do investigado; e surge com a proposta de estabelecer requisitos para a fundamentação da interceptação de comunicação telefônica.

Conclui-se que é admissível utilizar a interceptação telefônica como meio de prova, quando preenchidos os requisitos previstos na Lei da Interceptação Telefônica. A sua licitude está associada ao atendimento da lei e o respeito aos princípios estabelecidos pela Constituição. Mesmo que seja um meio de prova colhido a partir da violação dos direitos à intimidade e à liberdade de comunicação, torna-se lícita por auxiliar na coleta de provas de um crime com pena de reclusão, caracterizando uma defesa dos interesses da sociedade.

\section{REFERÊNCIAS}

CAPEZ, F.. Curso de Direito Penal: legislação penal especial. São Paulo: Saraiva, 2013.

GOMES, L. F.. Direito Processual Penal. São Paulo: Revista dos Tribunais, 2014.

MORAES, A.. Direito Constitucional. São Paulo: Atlas, 2015. OLIVEIRA, E. P.. Curso de Processo Penal. Rio de Janeiro: Lumen Juris, 2014.

PELLEGRINI, A.. O sistema brasileiro de interceptação telefônica. São Paulo: UNESP, 2013.

RABONEZE, R.. Provas obtidas por meios ilícitos. Porto Alegre: Síntese, 2012.

RANGEL, P.. Direito Processual Penal. Rio de Janeiro: Lumen Juris, 2015.
SILVA, E. A.. Interceptação Telefônica. São Paulo: Millenium, 2014.

SOUZA, S. R.. Interceptação Telefônica e provas. Rio de Janeiro: Forense, 2016.

STRECK, L. L.. As interceptações telefônicas e os direitos fundamentais. 2 ed. Porto Alegre: Livraria do Advogado, 2015.

TÁVORA, N.. Curso de direito processual penal. Salvador: JusPodvim, 2016.

TOURINHO FILHO, F. C.. Processo Penal. São Paulo: Saraiva, 2015.

A CBPC - Companhia Brasileira de Produção Científica (CNPJ: 11.221.422/0001-03) detém os direitos materiais desta publicação. Os direitos referem-se à publicação do trabalho em qualquer parte do mundo, incluindo os direitos às renovações, expansões e disseminações da contribuição, bem como outros direitos subsidiários. Todos os trabalhos publicados eletronicamente poderão posteriormente ser publicados em coletâneas impressas sob coordenação da Sustenere Publishing, da Companhia Brasileira de Produção Científica e seus parceiros autorizados. Os (as) autores (as) preservam os direitos autorais, mas não têm permissão para a publicação da contribuição em outro meio, impresso ou digital, em português ou em tradução. 